\title{
Phytochemical and Antioxidant Studies of Salvadora persica L. Stem \& Twig
}

\author{
Abhishek Gupta, Shikhar Verma, Pradeep Kushwaha, Sharad Srivastava, A K S Rawat ${ }^{\star}$ \\ Pharmacognosy \& Ethnopharmacology Division, CSIR- National Botanical Research Institute, Lucknow-226001
}

\begin{abstract}
Salvadora persica L. commonly known as Miswak and have immense medicinal value as anti-microbial and in prevention of tooth decay. Present study deals with phytochemical and antioxidant evaluation of $S$. persica twig and stem. Chloroform and ethanolic extracts from $S$. persica twig and stem are screened for antioxidant activity using, DPPH free radical scavenging activity. Methanolic extract has been studied through HPTLC. In S. persica twig, $\mathrm{IC}_{50}$ of chloroform extract and ethanolic extract was found to be $181.33 \pm 1.15 \mu \mathrm{g} / \mathrm{ml}$ and $197.00 \pm 1.73$ $\mu \mathrm{g} / \mathrm{ml}$ respectively, however in stem, $\mathrm{IC}_{50}$ of chloroform extract and ethanolic extract was found to be $187.33 \pm$ $0.57 \mu \mathrm{g} / \mathrm{ml}$ and $235.66 \pm 1.52 \mu \mathrm{g} / \mathrm{ml}$ respectively. Ascorbic acid is used as standard which showed IC ${ }_{50} 2.03 \pm$ $0.06 \mu \mathrm{g} / \mathrm{ml}$. In HPTLC studies the ferulic acid content was found to be $0.026 \%$ and $0.082 \%$ in $S$. persica stem and twig respectively. All the extracts showed significant in vitro antioxidant activity, chloroform extract showed the most potent activity followed by ethanolic extract. Ferulic acid, a potential antioxidant present in this species, has been studied through HPTLC. The presence of ferulic acid has not yet been reported and quantified in this species which may be utilized for the proper standardization of the drug.
\end{abstract}

Key words: Antioxidant activity, DPPH, Ferulic acid, Salvadora persica.

\section{INTRODUCTION}

The toothbrush tree, Salvadora persica, L., locally called miswak, is a member of family Salvadoraceae; it has been used by many communities as toothbrushes and has been scientifically proven to be very useful in the prevention of tooth decay, even when used without any other tooth cleaning methods. ${ }^{1-3} S$. persica is widely distributed in India, Africa, Saudi Arabia, Iran, Israel and Paki$\operatorname{stan}^{4}$

It has been reported that extracts of miswak posses various biological properties, including significant antibacterial, ${ }^{5,6}$ antifungal, ${ }^{7}$ and anti-plasmodial effects. ${ }^{8}$ Phytochemical investigation revealed that it contains alkaloids, glycosides, flavonoids, carbohydrates, tannins, saponins and steroids. ${ }^{9}$ It also contains oleic, linoleic, stearic acids, esters of fatty acids and aromatic acids, and some terpenoids. The major components from the essential oil of S. persica stem have been identified as 1,8-cineole (eucalyptol) (46\%), $\alpha$-caryophellene $(13.4 \%), \beta$-pinene $(6.3 \%)$, and $\quad$ 9-epi-(E)-caryophellene. ${ }^{10} \quad$ GC-MS analysis of the volatile oil extracted from $S$. persica leaves revealed benzyl nitrile, eugenol, thymol, isothymol, eucalyptol, isoterpinolene, and $\beta$-caryophyllene as important constituents. ${ }^{11}$

Sticks from $S$. persica have been analyzed for their soluble and total content of fluoride, calcium, phosphorus, and silica. There was a substantial amount of silica in the ashes of miswak. ${ }^{12}$ Three lignin glycosides have been reported from the stem of $S$. persica. ${ }^{13}$ The minor components such as volatile oils, flavonoids may, to some degree augment the pharmacological effects of the plant. ${ }^{14}$ An indole alkaloid salvadoricine known to occur in leaves have also been isolated
Submission Date :05-06-2014 Revision Date : :25-08-2014 Accepted Date : :26-11-2014

DOI: 10.5530/ijper.49.1.10 Correspondence Address Dr. A K S Rawat

Head, Pharmacognosy \& Ethnopharmacology Division,

CSIR- National Botanical Research Institute, Lucknow-226001

Email: pharmacognosy1@ rediffmail.com

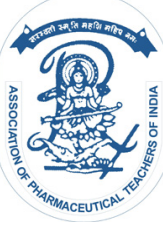

www.ijper.org 
from undifferentiated tissues of $S$. persica..$^{15}$ It has been shown to contain trimethylamine, salvadorine, chloride, fluoride, silica, sulphur, mustard oil, vitamin C, resins and traces of tannins, saponins, flavonoids and sterol. ${ }^{16}$ Roots also contain alpha amylase. ${ }^{17}$ The antioxidant activity of $S$. persica stem has been performed earlier; ${ }^{5}$ however present study was performed to compare the antioxidant property of stem and twig of S. persica. Considering the value of this drug in traditional practices, the present study was performed to develop comparative phytochemical parameters and evaluation of antioxidant potential on stem and twig of this species.

\section{MATERIALS AND METHODS}

\section{Chemicals and Reagents}

1,1Diphenyl -2-picrylhydrazyle (DPPH), was obtained from Sigma Aldrich Co. All other chemicals used were of analytical grade.

\section{Plant material}

The plant specimen i.e. dried stem and twig of $S$. persica were collected from Barhmer, Rajasthan, India in 2008. The plant was authenticated by Dr. AKS Rawat, NBRI. A voucher specimen (262542) has been submitted in institute's herbarium.

\section{Preparation of Plant Extracts}

The fresh plant material was collected, thoroughly washed with water to remove all debris and then shade dried. The dried material was powdered by using electric grinder at 100 mesh size. Extraction was performed by soxhlation process in two steps. Firstly the powdered material was defatted under soxhlet assembly using 250 $\mathrm{mL}$ of $98 \%$ ether for 6 hours. This is followed by 9 hours soxhlation of defatted powder by using $250 \mathrm{~mL}$ of chloroform as solvent. Same procedure was used to obtain ethanolic extract, after defatting of crude drug it was extracted with $250 \mathrm{~mL}$ of $99.9 \%$ ethanol for 6 hours.

The final extracts were passed through Whatman No. 1 filter paper. The filtrates obtained were concentrated under vacuum in a rotary evaporator at $40^{\circ} \mathrm{C}$ and stored at $4^{\circ} \mathrm{C}$ for further use. The crude extracts were obtained by dissolving a known amount of dry extract in 98\% methanol to obtain a stock solution of $1000 \mu \mathrm{g} / \mathrm{ml}$. The stock solutions were serially diluted with the respective solvents to obtain lower dilutions $(25,50,100,125,150$, 200, 250, 300 and $500 \mu \mathrm{g} / \mathrm{ml}$ ).

\section{Physicochemical and Phytochemical Studies}

Physicochemical and Phytochemical studies like extractive values, total ash, acid insoluble ash, total sugar, starch, tannin, and phenols were calculated from the shade-dried and powdered (60 mesh) plant material. ${ }^{18-21}$ Antioxidant Activity (DPPH Free Radical Scavenging Activity)

Antioxidant activity of the plant extracts and standard was assessed on the basis of the radical scavenging effect of the stable DPPH free radical by the method previously described. ${ }^{22}$ The diluted working solutions of the test extracts were prepared in methanol. Ascorbic acid was used as the standard in solutions ranging from 1 to $50 \mu \mathrm{g} / \mathrm{ml}$. $0.002 \%$ DPPH solution in methanol was prepared. Then $2 \mathrm{ml}$ of this solution was mixed with 2 $\mathrm{ml}$ of sample solutions (ranging from $25 \mu \mathrm{g} / \mathrm{ml}$ to 500 $\mu \mathrm{g} / \mathrm{ml}$ ) and the standard solution to be tested separately. These solution mixtures were kept in the dark for 30 min and optical density was measured at $517 \mathrm{~nm}$ using a Shimadzu spectrophotometer against methanol. The blank used was $2 \mathrm{ml}$ of methanol with $2 \mathrm{ml}$ of DPPH solution $(0.002 \%)$. The optical density was recorded and percentage of inhibition was calculated using the equation: $\%$ of inhibition of DPPH activity $=(\mathrm{A}-\mathrm{B}) / \mathrm{A} \times$ 100 ; where $A$ is optical density of the blank and $B$ is optical density of the sample.

\section{HPTLC Studies}

Air dried $\left(45-55^{\circ} \mathrm{C}\right)$ powdered stem and twig of S. persica $(2.0 \mathrm{~g})$ in triplicate were extracted separately with 3 X $20 \mathrm{ml}$ methanol. Extracts were concentrated under vacuum and redissolved in methanol, filtered and finally made up to $100 \mathrm{ml}$ with methanol prior to HPTLC analysis. Reagents used were from Merk (Germany) and standard ferulic acid was procured from Sigma-Aldrich (Steinheim).

\section{Chromatographic Conditions}

Chromatography was performed on Merk HPTLC precoated silica gel $60 \mathrm{GF}_{254}(20 \mathrm{X} 20 \mathrm{~cm})$ plates. Methanolic solutions of samples and standard compound ferulic acid of known concentrations were applied to the layers as $6 \mathrm{~mm}$-wide bands positioned $15 \mathrm{~mm}$ from the bottom and $15 \mathrm{~mm}$ from side of the plate, using Camag Linomat $\mathrm{V}$ automated TLC applicator with nitrogen flow providing a delivery speed of $150 \mathrm{nl} / \mathrm{s}$ from application syringe. These conditions were kept constant throughout the analysis of samples.

\section{Detection and Quantification of Ferulic Acid}

Following sample application, layers were developed in a Camag twin trough glass chamber which was pre-saturated with mobile phase of toluene: ethyl acetate: formic acid (5:5:1) till proper separation of bands up to 8 $\mathrm{cm}$ height. After development, layers were dried with an air dryer and ferulic acid was simultaneously quantified 


\begin{tabular}{|l|c|c|c|c|c|c|c|c|}
\hline \multicolumn{7}{|c|}{ Table 1: Phytochemical Screening of S. persica (Twig \& Stem) } \\
\hline & \multicolumn{2}{|c|}{ Hexane } & \multicolumn{2}{c|}{ Chloroform } & \multicolumn{2}{c|}{ Alcohol } & \multicolumn{2}{c|}{ water } \\
\hline & Twig & Stem & Twig & Stem & Twig & Stem & Twig & Stem \\
\hline Alkaloids & - & - & + & + & + & - & - & + \\
\hline Glycosides & - & - & - & - & + & + & + & + \\
\hline Tannins & - & - & - & - & + & - & + & + \\
\hline Saponins & - & - & - & - & + & + & + & + \\
\hline Flavonoids & - & - & - & - & + & + & + \\
\hline Protein & - & - & - & - & - & - & - & + \\
\hline Carbohydrates & - & - & - & - & + & + & + \\
\hline
\end{tabular}

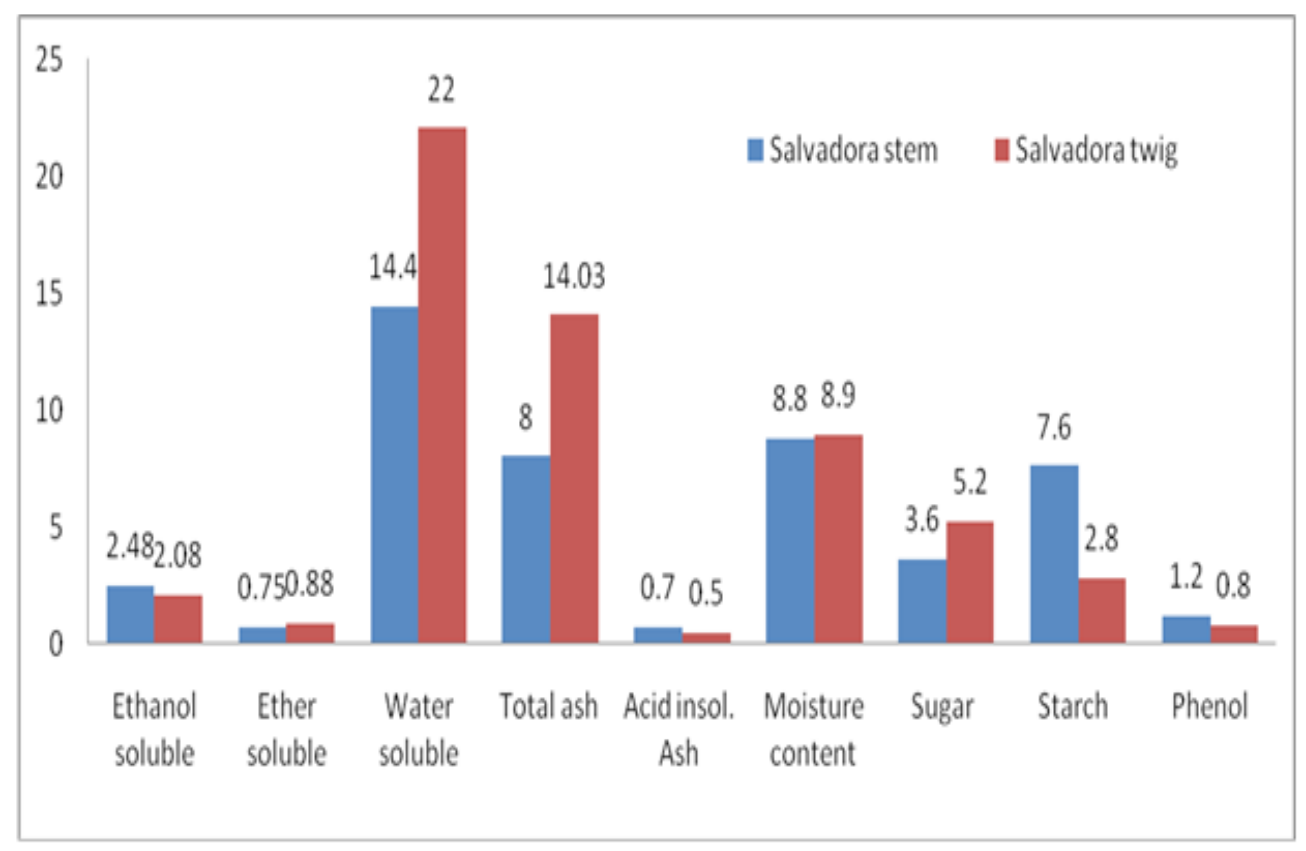

Figure 1: Percentage physicochemical values of S. persica stem and twig

using Camag TLC scanner model 3 equipped with Camag Wincats IV software. Following scan conditions were applied: slit width, $5 \mathrm{~mm} \times 0.45 \mathrm{~mm}$; wavelength, $320 \mathrm{~nm}$; and absorption-reflection mode. In order to prepare calibration curves, stock solution of ferulic acid $(1 \mathrm{mg} / \mathrm{ml})$ was prepared and various volumes of the solution were analyzed through HPTLC, calibration curves of peak area vs. concentration were also prepared.

\section{RESULTS}

\section{Phytochemical screening}

Phytochemical screening for the hydro-alcoholic extract showed positive test for flavonoids, proteins, carbohydrates, glycosides, phenolic compounds and saponins, Table 1.

\section{Physicochemical Studies}

Parameters such as moisture content, extractive values (Water, alcohol and ether soluble), total ash and acid insoluble ash values, total sugar, total starch, and total phenolics were determined, Figure 1.

\section{Antioxidant activity}

Invitro antioxidant study of $S$. persica stem (SS) \& twig (ST) was performed using two different extracts viz. ethanolic and chloroform extract. In this study ST chloroform extract showed the least $\mathrm{IC}_{50}$ value of $181.33 \pm 1.15 \mu \mathrm{g} / \mathrm{ml}$. Standard ascorbic acid showed IC50 value of $2.03 \pm 0.06 \mu \mathrm{g} / \mathrm{ml}$, Table 2 .

\section{HPTLC Studies}

Calibration curve of ferulic acid showed $\mathrm{r}^{2}$ of 0.949 and $R_{f}$ of ferulic acid was found to be $0.69 \pm 0.006$. Quantification of ferulic acid in the samples of $S$. persica stem and twig has been performed and the ferulic acid was found to be $0.026 \%$ and $0.082 \%$ respectively. A Densitogram and Banding pattern obtained from extract shows ferulic acid, Figure 2 and 3. 


\section{Table 2: Antioxidant activity of S. persica (Twig \& Stem)}

\begin{tabular}{|c|c|}
\hline Sample & DPPH assay IC-50( $\boldsymbol{\mu g} / \mathrm{mL})$ \\
\hline AA-std & $2.03 \pm 0.06$ \\
\hline SS-chloroform & $187.33 \pm 0.57$ \\
\hline SS-ethanolic & $235.66 \pm 1.52$ \\
\hline ST-chloroform & $181.33 \pm 1.15$ \\
\hline ST-etanolic & $197.00 \pm 1.73$ \\
\hline
\end{tabular}

AA- Ascorbic Acid; SS- Salvadora Stem; ST-Salvadora Twig

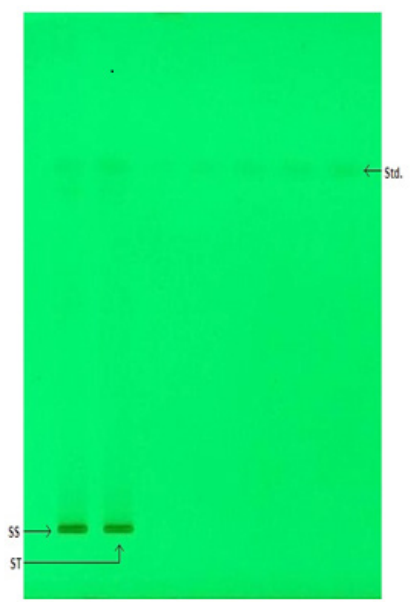

Figure 2: HPTLC profiles of Methanolic extract of S. persica stem (SS), twig (ST) \& Standard (Ferulic acid)

\section{DISCUSSION}

Ascorbic acid (standard compound) showed highest significant and potent antioxidant activity in DPPH free radical scavenging method. Chloroform extract showed the most potent activity followed by ethanolic extract.

Presence of phenolic compounds in S. persica suggests that the antioxidant activity may be due to the polyphenolic content. Identification of all chemical constituents in extract those are responsible for antioxidant activity requires further investigation, the crude extracts merits further experiments in vivo. Ferulic acid, a potential antioxidant present in this species, has been studied through HPTLC. The presence of ferulic acid has not yet been reported and quantified in this species which may be utilized for the proper standardization of the drug.

Present study showed new natural antioxidant that can replace the synthetic ones to be used in foods and cosmetics. Thus, the effective source of $S$. persica could be employed in all medicinal preparations to combat myriad diseases associated with oxidative stress and related disorders.

\section{ACKNOWLEDGEMENTS}

The authors are thankful to Director, NBRI for providi-

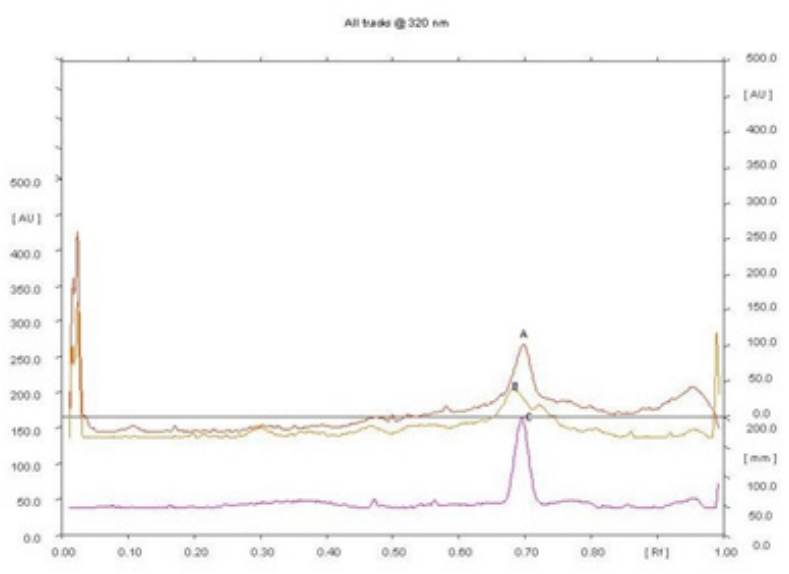

Figure 3: Densitometric chromatogram of S. persica stem, twig and ferulic acid

(A: Methanolic Extract of twig; B: Methanolic extract of stem; C: Standard Ferulic acid)

ing all the facilities (under OLP-0077) to conduct this research work, authors are also thankful to CSIR for financial grant under CSIR-EMPOWER scheme.

\section{CONFLICT OF INTEREST}

The authors declare no conflict of interest

\section{REFERENCES}

1. Chaurasia A, Patil R, Nagar A. Miswak in oral cavity-An update. Journal of Oral Biology and Craniofacial Research 2013; 3(2): 98-101.

2. Alili N, Türp JC, Kulik Eva M, Waltimo T. Volatile compounds of Salvadora persica inhibit the growth of oral Candida species. Archives of Oral Biology 2014; 59 (5): 441-7.

3. Almas AK, Almas K. Miswak (Salvadora persica chewing stick): the natural tooth brush revisited. Odontostomatol Trop 2014; 37(145): 27-39.

4. Anonymous, The Wealth of India, Vol. IX, Publication and Information Directorate CSIR, Lucknow; 1972. p. 194-5.

5. Al-sieni Al. The antibacterial activity of traditionally used Salvadora persica L. (miswak) and Commiphora gileadensis (palsam) in Saudi Arabia. Afr J Tradit Complement Altern Med. 2013; 11(1): 23-7.

6. Rasouli GAA, Rezaei A, Hosein MSS, Yaghoobee S, Khorsand A, Kadkhoda $Z$, et al. Inhibitory activity of Salvadora persica extracts against oral bacterial strains associated with periodontitis: An in-vitro study. Journal of oral biology and cranio facial research 2014; 4: 19-23.

7. Noumi E, Snoussi M, Hajlaoui H, Valentin E, Bakhrouf A. Antifungal properties of Salvadora persica and Juglans regia L. extracts against oral Candida strains. Eur J Clin Microbiol Infect Dis. 2010; 29(1): 81-8.

8. Ali H, König GM, Khalid SA. Evaluation of selected Sudanese medicinal plants for their in vitro activity against hemoflagellates, selected bacteria, HIV- 
1-RT and tyrosine kinase inhibitory, and for cytotoxicity. J Ethnopharmacol 2002; 83(3): 219-28.

9. Khan W, Mujum A, Shaikh T, Katekar SM. Tambe R, Rub RA. Pharmacognostic and Preliminary Phytochemical investigation of Salvadora persica Linn (Salvadoraceae). Research Journal of Pharmacognosy and Phytochemistry 2010; 2(4): 319-23.

10. Alali F, Hudaib M, Aburjai T, Khairallah K, Al-Hadidi N. GC-MS Analysis and Antimicrobial Activity of the Essential Oil from the Stem of the Jordanian Tooth brush Tree Salvadora persica. Pharma Biol 2005; 42(8): 577-80.

11. Alali F, Al-Lafi T. GC-MS analysis and bioactivity testing of the volatile oil from the leaves of the toothbrush tree Salvadora persica L. Nat Prod Res. 2003; 17(3): 189-94.

12. Akhtar J, Siddique KM, Bi S, Mohd MA. review on Phytochemical and pharmacological investigations of miswak (Salvadora persica Linn). J Pharm bioall Sci. 2011; 3(1): 113-7.

13. Kamal MS, Ohtani K, Assaf MH, Kasai R, El-Shanawani MA, Yamasaki K. Lignan glycoside from stems of Salvadora persica L. Phytochemistry 1992; 31(7): 2469-71.

14. Ahmad H, Ahmad N. Ethnobotany, Pharmacology and Chemistry of Salvadora persica L. A Review. Research in Plant Biology 2012; 2(1): 22-31.
15. Mathur S, Batra A. Production of an Indole Alkaloid from Callus Cultures of Salvadora Persica L. International Journal of Chemical. Environmental and Pharmaceutical Research 2011; 2(2-3): 141-5.

16. Elvin-Lewis M. The therapeutic potential of plants used in dental folk medicine. Odontostomatol Trop. 1982; 5(3): 107-17.

17. Mohamed SA, Almulaiky YQ, Ahmed YM, Al-Bar OAM, Ibrahim HI. Purification and characterization of a-Amylase from Miswak Salvadora persica. BMC Complementary and Alternative Medicine 2014; 14(1): 119.

18. Peach K,Tracy MV. Modern Methods of Plant Analysis. Vol III and IV Springer, Heidelberg; 1955. p. 258-61.

19. Anonymous. Indian pharmacopoeia, Government of India, Ministry of Health and Family Welfare, Controller of Publications, New Delhi; 2007. p. 191.

20. Anonymous. Official methods of Analysis (AOAC), $4^{\text {th }}$ edn. Association of Official Chemists, Inc. U.S.A; 1984. p. 187-8.

21. Anonymous. Ayurvedic Pharmacopeoeia of India. Part I, vol I. Department of Health, Ministry of Health and Family Welfare, Government of India, New Delhi; 2004. p. 152-165.

22. Verma S, Gupta A, Kushwaha P, Khare V, Srivastava S, Rawat AKS. Phytochemical Evaluation and Antioxidant Study of Jatropha curcas Seeds. Phcog J. 2012; 4(29): 5-54. 